Revista da Rede Brasileira de História da Geografia e Geografia Histórica

\title{
Una cartografía pictórica de 1730
}

El análisis visual asistido por computadora (AVAC) como herramienta para la historiografía urbana de la Villa de Aguascalientes

Uma cartografia pictórica de 1730. A análise visual assistida por computadora como ferramenta para a historiografia urbana da Villa de Aguascalientes

A pictorial cartography from 1730. Computer assisted visual analysis as a tool for the urban historiography of the Villa de Aguascalientes

Marco Alejandro Sifuentes Solís y Jorge Carlos Parga Ramírez

\section{(2) OpenEdition}

Journals

Edición electrónica

URL: https://journals.openedition.org/terrabrasilis/1271

DOI: 10.4000/terrabrasilis. 1271

ISSN: 2316-7793

Editor

Rede Brasileira de História da Geografia e Geografia Histórica

Referencia electrónica

Marco Alejandro Sifuentes Solís y Jorge Carlos Parga Ramírez, «Una cartografía pictórica de 1730» Terra Brasilis [En línea], 4 | 2015, Publicado el 12 febrero 2015, consultado el 05 diciembre 2022. URL: http://journals.openedition.org/terrabrasilis/1271 ; DOI: https://doi.org/10.4000/terrabrasilis.1271

Este documento fue generado automáticamente el 5 diciembre 2022

All rights reserved 


\section{Una cartografía pictórica de 1730}

El análisis visual asistido por computadora (AVAC) como herramienta para la historiografía urbana de la Villa de Aguascalientes

Uma cartografia pictórica de 1730. A análise visual assistida por computadora como ferramenta para a historiografia urbana da Villa de Aguascalientes

A pictorial cartography from 1730. Computer assisted visual analysis as a tool for the urban historiography of the Villa de Aguascalientes

Marco Alejandro Sifuentes Solís y Jorge Carlos Parga Ramírez

\section{Introducción}

1 La moderna ciudad de Aguascalientes (Figura 1), capital del estado del mismo nombre, uno de los más pequeños de la República Mexicana, es una urbe que actualmente cuenta con cerca de un millón de habitantes en su zona metropolitana y es uno de los centros fabriles de mayor potencial de negocios y de proyección internacional gracias al establecimiento de dos plantas de NISSAN destinadas a la producción de unidades automotrices para el mercado mundial. No obstante esta aura de modernidad, tuvo su origen como una simple villa novohispana en el siglo XVI, perteneciente al Reino de la Nueva Galicia de la Nueva España, siendo prácticamente contemporánea a la promulgación de las Ordenanzas de Felipe II. Durante sus primeros años padeció innumerables infortunios y calamidades que casi provocaron su despoblamiento, pero poco a poco, conforme transcurrió el tiempo, se transformó en una pujante urbe que en muchos sentidos ha trascendido por el hecho de que en múltiples ocasiones ha sido "laboratorio" de experimentación e implantación de numerosas políticas nacionales a lo largo de los años, así en vivienda, como en sistemas nacionales de riego o en la planeación urbana y territorial. 
Figura 1: Localización de la ciudad de Aguascalientes en la República Mexicana

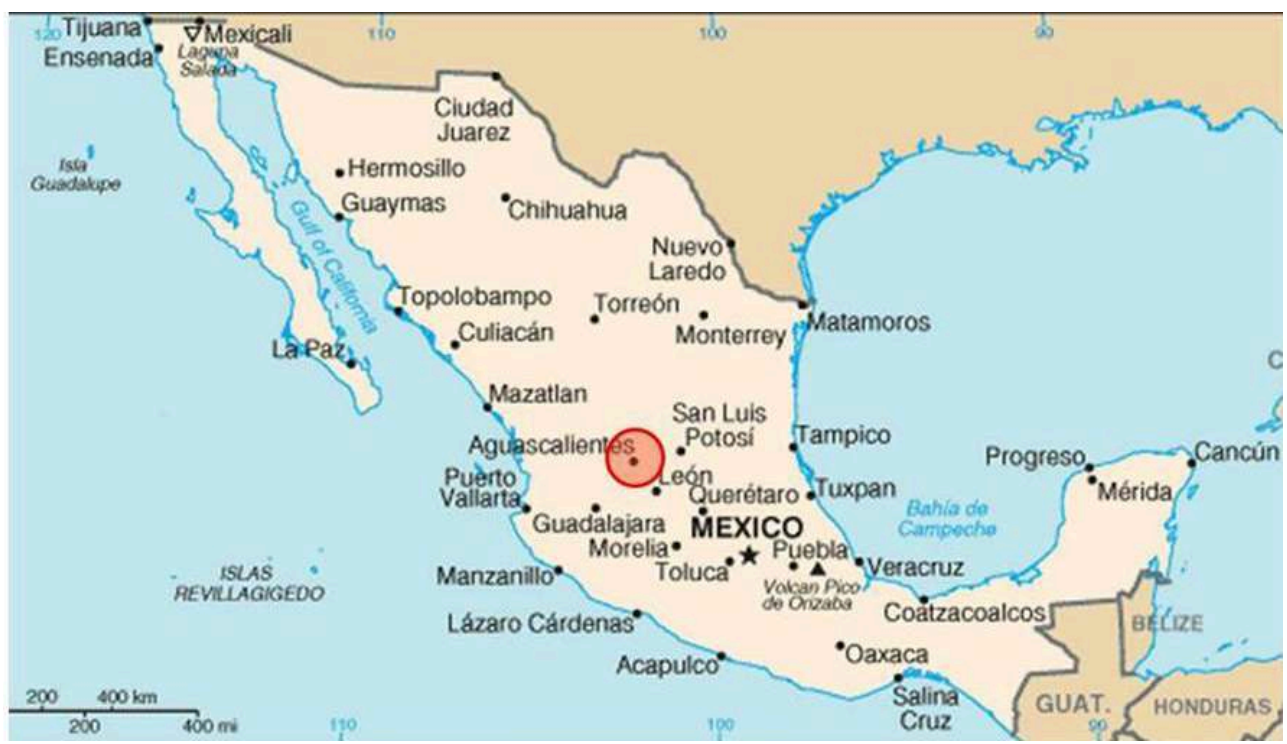

Fuente: http://www.map.mx/img/upload/mexico-cia-factbook-map.png

Contrastando con lo anterior, siguen persistiendo muchos vacíos de conocimiento en torno a su desarrollo histórico como ciudad, rango que adquirió en 1824, a lo que desafortunadamente ha contribuido la más bien escasa cartografía disponible.

Ante la carencia de suficiente documentación gráfica histórica anterior a 1855, fecha del Plano de las Huertas elaborado por Isidoro Epstein, ${ }^{1}$ el saber producido al momento sobre la cartografía de la ciudad de Aguascalientes ha dependido muchas veces de las sentencias, creencias o conjeturas elaboradas con poco rigor por algunos historiadores y cronistas, que se han tomado como verdades consagradas y repetido acríticamente de modo persistente por la historiografía a lo largo de los años, vicio del que nosotros mismos no hemos escapado en otro tiempo. En similares ocasiones la documentación escrita existente ha propiciado lecturas diversas acerca de un mismo asunto, más allá del sentido literal de la fuente de origen.

Pensemos por ejemplo en una repetida línea del auto del Oidor de la Audiencia de Guadalajara, Gaspar de la Fuente (quien en 1609 prácticamente dictó los lineamientos para una auténtica refundación de la villa de Aguascalientes), pasaje que hemos visto publicado como “... que en la escuadra frontera a la del sureste la iglesia...", ${ }^{2}$ y del que, a la vista de un documento de 1830-31 que transcribe los autos de 1609 y 1644 (providencialmente llegado a nuestras manos), ${ }^{3}$ nosotros leemos “... y que la cuadra frontera a la parte del sur esté la Yglesia...", ${ }^{4}$ lo cual otorga a la expresión otro significado, que implica que la isla para la parroquia de la villa debía hacerse al sur de la plaza, parece que más bien en el ángulo suroeste (que paradójicamente un respetado historiador admite, a pesar de su lectura de la susodicha línea de don Gaspar), ${ }^{5}$ en donde tiempo después se levantó la casa del Vínculo del Mayorazgo de Ciénega de Mata (hoy edificio sede del gobierno estatal), idea que fundamos nosotros en los rituales que Bernardo Vargas Machuca, desde 1599, había consignado para la fundación, asiento y traza de poblaciones en territorios conquistados y pacificados, en uno de cuyos pasajes clave se lee que el que conquistare la tierra: "embaynará su espada y luego en el instante hará hincar una cruz, que para ello tendrá hecha, a una esquina de la plaza, que será a la parte que ya tendrá elegida para la iglesia". ${ }^{6}$ 
5 En ocasiones la información histórica disponible no contribuye a precisar o aclarar las dudas, debido a que con frecuencia el historiador trabaja la fuente de origen como fuente objetiva, sin considerar la subjetividad que arrastra toda actividad humana, como es el caso del registro de hechos. El presente artículo, así, expone los resultados preliminares de un análisis de imagen que pretende contribuir a despejar algunas incógnitas persistentes sobre el desarrollo de la villa a principios del siglo XVIII. Haciendo uso de fuentes primarias escritas y gráficas, especialmente una cartografía pictórica de 1730, así como su contrastación con la evidencia tangible actual de la traza de la ciudad de Aguascalientes, el texto confirma la idea de que el dibujo del territorio lo inventa como tal (Russo, 2007), y demuestra que el anónimo autor de dicha representación iconográfica no pudo dejar de ceñirse a las convenciones pictóricas de su época, dando como resultado una imagen idealizada de la villa que sin embargo, triangulada con otras fuentes primarias, proporciona suficientes pistas para la construcción/interpretación de un momento en su devenir y para desmitificar asunciones, dudas y confusiones que sobre el pasado de la ciudad de Aguascalientes se han producido en la historiografía urbana especializada.

\section{Nota breve sobre el estatuto epistémico de la imagen}

6 Para comenzar a establecer un espacio de discusión epistemológica acerca de la imagen cartográfico-pictórica como fuente para la historiografía urbana, es necesario primero consignar su estatuto epistémico-icónico, lo que nos conduce a dilucidar la concepción misma de la realidad visual, que durante mucho tiempo ha estado sujeta a la tradición positivista, cuantitativista y objetivista de lo natural y lo social. Al respecto, Hernández señala:

Digamos para empezar que desde una gran parte de la producción científica de lo social y su relación con las imágenes, la concepción de lo visual fue enormemente influenciada por la tradición positivista de la psicología. En primer lugar porque dominaba la idea de que era posible hacer observaciones objetivas de la realidad. Y en segundo lugar porque desde el modelo conductista la experiencia visual se asumió como una respuesta de un organismo [a un] determinado estímulo visual real; y después, bajo las teorías de la percepción, como una elaboración mental del mismo estímulo. El problema principal era de estímulo, no de interpretación, la realidad era sólo una y en ella estaban contenidos los mensajes que el individuo, más allá su cerebro, procesaba según la capacidad perceptiva de éste. Es decir, se asumió que la realidad objetiva proporciona estímulos visuales (entre otros) independientes del sujeto, éstos por lo tanto pueden ser percibidos y procesados con mayor o menor objetividad por los sujetos. $^{7}$

8 A semejante concepción iba unida la idea de que la cognición era de naturaleza individual, pero en la epistemología actual "La experiencia cognitiva es de naturaleza colectiva o de otra forma no puede ser cognitiva”, es decir, “... la percepción no es un conocimiento directo de la realidad objetiva, sino que opera mediante categorizaciones construidas intersubjetivamente"; lo que significa que "... vemos a través de las categorías cognitivas construidas socialmente". ${ }^{8}$ Incluso disciplinas como la Historia misma siguen empleando una concepción del dato visual como fuente objetiva. Al respecto, afirma Hernández que "falta explicitar una orientación epistemológica donde 
se tome en cuenta la discusión sobre la subjetividad y la reflexividad en la construcción de los datos visuales, que implica el posicionamiento y la intencionalidad del autor". ${ }^{9}$

$\mathrm{Y}$ a tal efecto no pueden ser desestimados los lenguajes verbal y visual; de este modo, "Se debe entonces considerar la conjunción de ambos lenguajes en la investigación, más que la sustitución de uno por el otro"; y esto vale así para la investigación en general como para la investigación histórica; el análisis de lo visual "debe contribuir a deconstruir el proceso sociocultural de las experiencias visuales particulares", ${ }^{10}$ que finalmente son producto de una cognición social, colectiva, dado que están inscritas en procesos intersubjetivos, pues “.... el potencial de la imagen en la práctica de la investigación social no es solo [sic] ilustrar, sino analizar [...] cómo lo visual interpela discursos, subjetividades, memorias colectivas, identidades políticas". ${ }^{11}$

Por otro lado, lo visual se inserta en un régimen escópico determinado social, política y culturalmente y que además supone lo que puede ser conocido en lo que puede ser visto, es decir, una suerte de episteme escópica. ${ }^{12}$ En síntesis, en la epistemología actual el ojo es considerado como un "dispositivo de producción cognitiva que tiene que vérselas con algo más que puras formas, con algo más que mera opticalidad retiniana", ${ }^{13}$ de suerte que hemos pasado de una epistemología que concibe el dato visual como algo objetivo que sólo hay que recabar o consignar, sin involucramiento del investigador, hasta aquella que lo concibe como algo construido subjetivamente y que lo interpreta con plena conciencia de su intervención bajo procesos de negociación intersubjetiva. El examen de una imagen del pasado, como en el caso que nos ocupa, no sólo ha de considerar los propios procesos subjetivos del autor de la misma, para lo cual el historiador tiene que echar mano de ciencias y procedimientos auxiliares (como el análisis de imagen), sino también la necesidad de "negociar" sus sentidos con los propios de quien la analiza en la actualidad.

11 En esta dirección, los pintores-cartógrafos, como sugiere Mangieri al referirse a la construcción de la ciudad desde la subjetividad y narratividad del lector in urbis -y nosotros añadiríamos, la construcción de la imagen de la ciudad a través, entre otros recursos, de su representación cartográfica-, tomaron de sus "enciclopedias locales" los elementos para construir su propia lectura de su particular y fabulada experiencia con los urbemas ${ }^{14}$ del contexto social de su época.

\section{La cuadrícula en el imaginario social hispanoamericano}

12 Esa lectura in urbis surge de la fábula creada por el ambiente del momento y los urbemas son, como se apunta, producto de la visión del mundo tanto religioso como práctico, surgidos como herencia de la intensa y prolífera colonización del Nuevo Mundo y de las "ordenanzas" para ocupar el territorio durante los siglos XVI y XVII.

13 En apego a lo que Hernández señala sobre la necesidad de echar mano de varias ciencias y procedimientos auxiliares para explicar el fenómeno histórico, en nuestro caso la imagen de la ciudad, aquí recurrimos a la propia historia y a la cartografía -bajo tratamientos digitalizados basados en lo que se ha dado en llamar "análisis visual y textual asistido por computadora" (AVTAC) ${ }^{15}$ para entender la concepción o visión del mundo que fue reflejada en la "pintura" de la que trata este artículo. 

oportunidad de reedificar, de aprovechar la nueva oportunidad para realizar una utopía; habrá que recordar que la mayoría de las ciudades obedecía a un crecimiento orgánico de impulsos de aliento y desaliento, sin un aparente orden, lo que se reflejaba en su traza de geometría compleja y poco identificable con una visión ordenada, clara y fácil de interpretar, es decir, de una geometría "euclidiana". romana como una disposición de orden en todos los ámbitos, en la pintura, la escultura, los espacios habitables y en general en la arquitectura urbana que de manera específica fue instrumentada con modelos radiales -con un centro intrínseco- o una retícula, por su orden racional, de disposición ortogonal y regularmente geométrica, tomada como paradigma para la ocupación del territorio y la ciudad en respuesta al desorden y organicidad medievales. ${ }^{16}$

La España educada y la elite de la nobleza que tomaba decisiones, observó con avidez las ideas renacentista ante el compromiso y la oportunidad de crear un mundo nuevo ordenado, higiénico y claro. Un ejemplo patente de la permeabilidad de esas ideas lo patentiza la creación del campamento de Santa Fe (Figura 2), dispuesto por los Reyes Católicos para realizar desde ahí la campaña y conquista de Granada, último reducto árabe en España, tiempo antes del encuentro del nuevo continente.

Figura 2: Asentamiento de Santa Fe, Granada, España

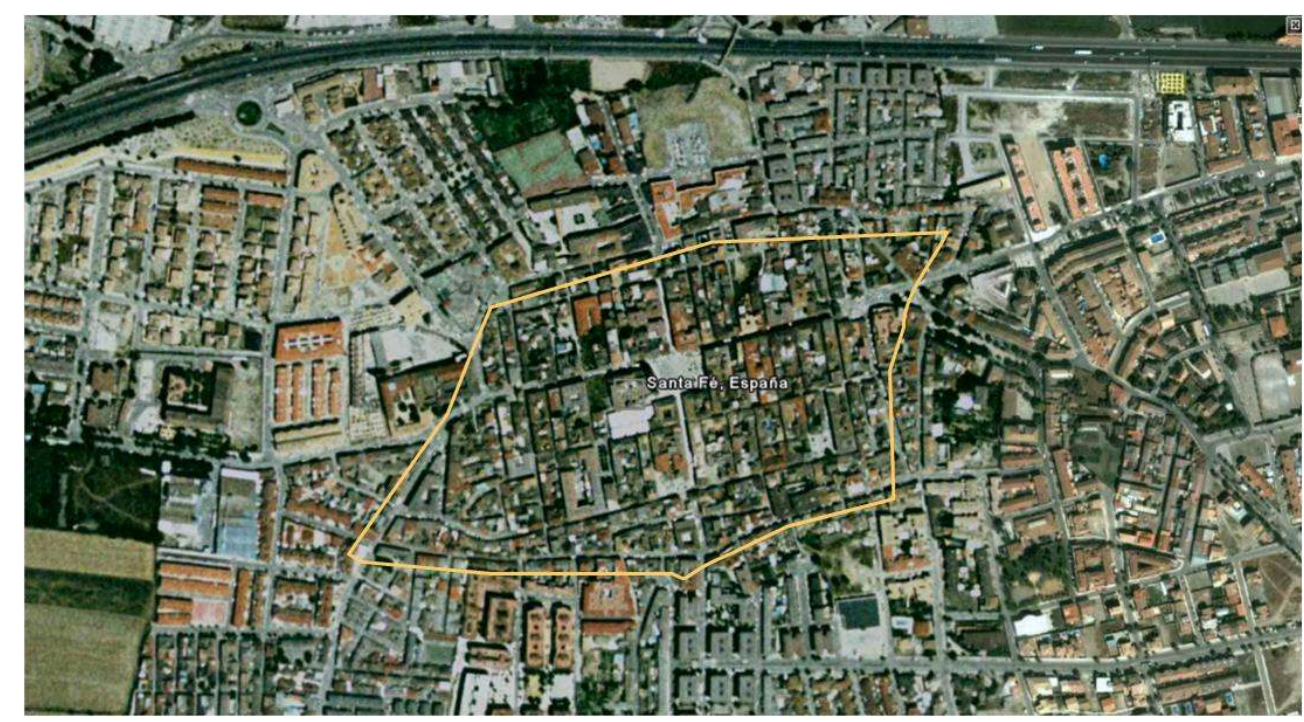

Fuente: Google Earth, 2011

Esta disposición se propagó ante la oportunidad de ocupar y crear nuevos asentamientos dentro y fuera del territorio español, así como la anexión de los americanos, y se convirtió rápidamente en los usos, costumbres y disposiciones sobre las Indias y de su población, que finalmente fueron recogidos por el rey para tornarse en la célebre "Cédula de Felipe II" (Figura 3), que tiempo después se convirtió en lo que se puede considerar como muestra de la "experiencia cognitiva convertida en voluntad colectiva" que menciona Hernández. 
Figura 3: Sección de la Cédula de Felipe II acerca de los usos, costumbres y disposiciones sobre las Indias y de su población

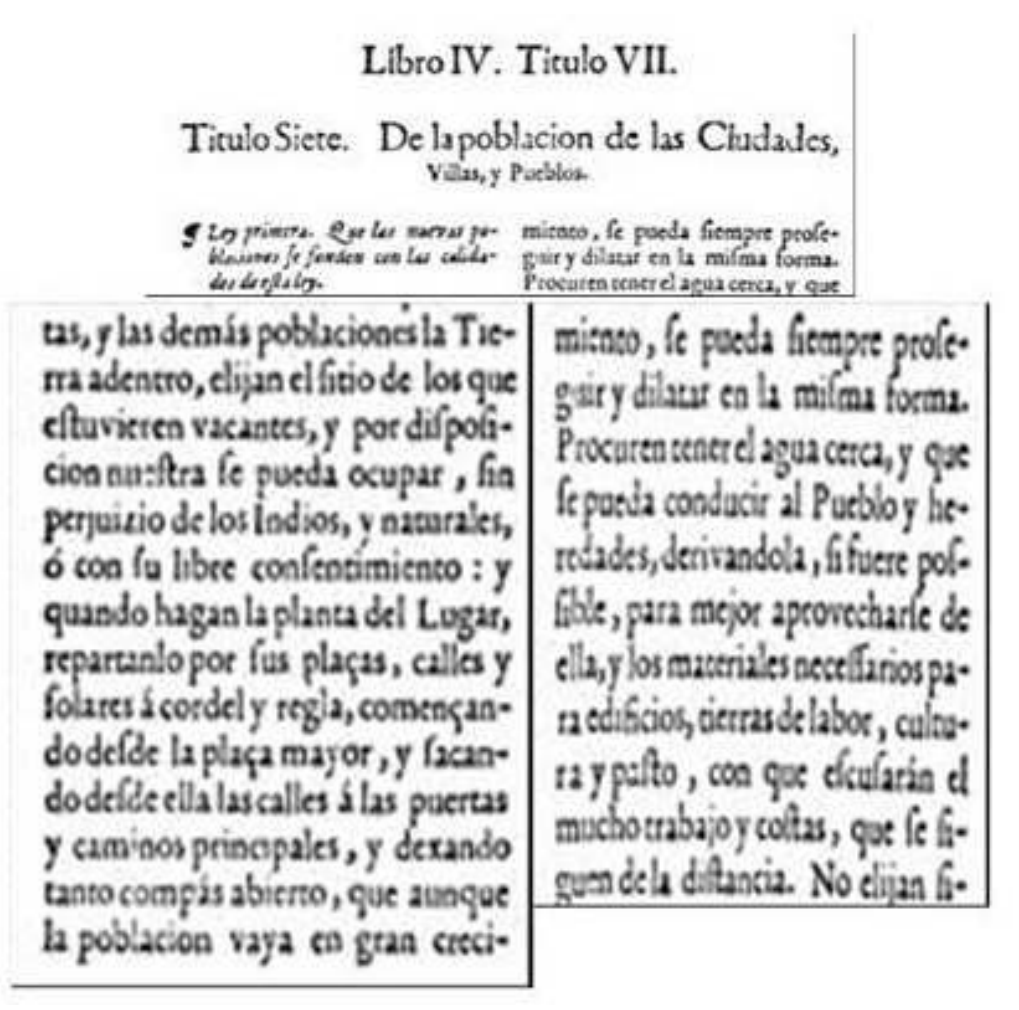

Fuente: http://www.gabrielbernat.es/espana/leyes/rldi/indice/indice.html

La aplicación concreta de estas disposiciones es ilustrada por Federico Fernández Christlieb y Pedro S. Urquijo (Figura 4). 
Figura 4: Propuesta hipotética para un nuevo asentamiento

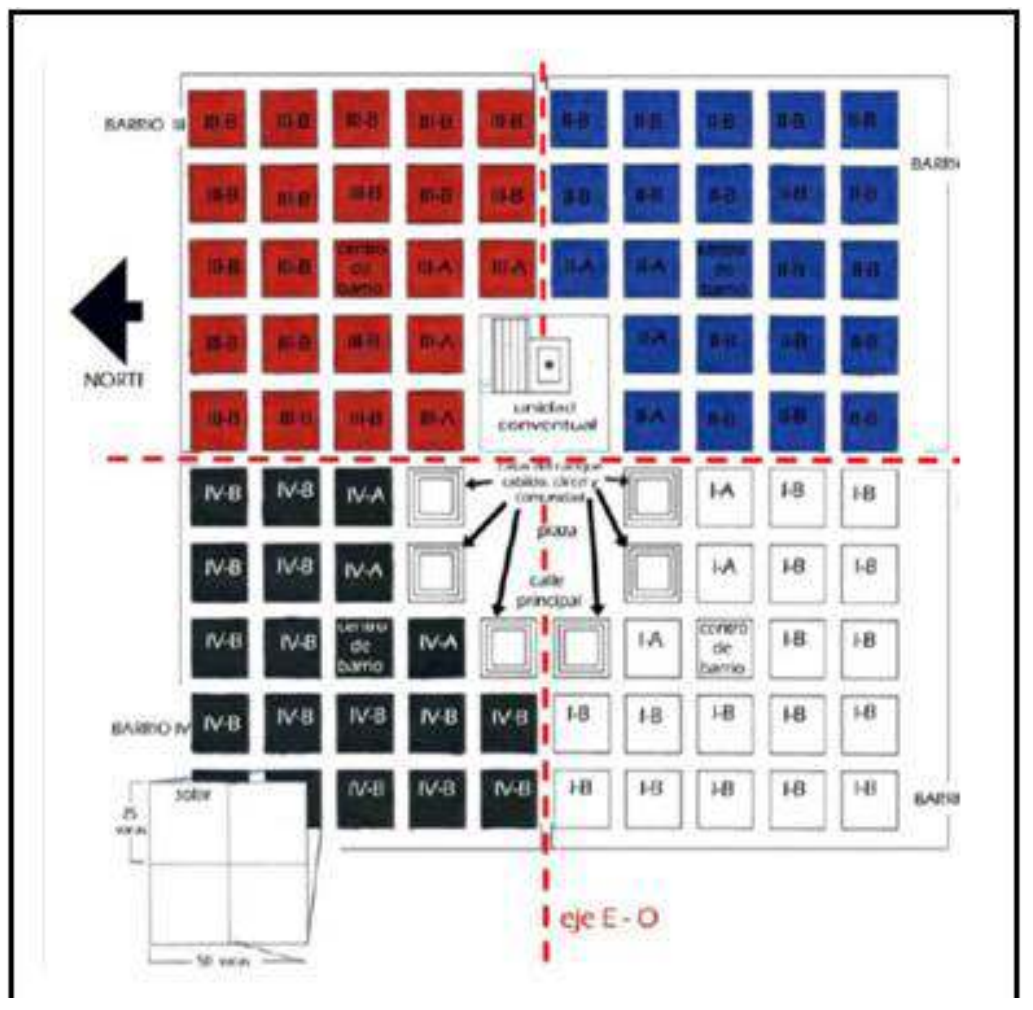

Según Federico Fernández Christlieb y Pedro S. Urquijo (2006, p. 53)

19 La disposición concluye en un damero de cuadros que parten de una plaza principal en donde se ubicarían los edificios emblemáticos de los poderes religioso, civil y comercial, de la cual partían calles dividiendo el territorio en parcelas, las cercanas para los principales y el resto para los naturales. Parcelas representadas por cuadros señalados con el número romano del barrio al que pertenecían: aquéllos seguidos de la letra $\mathrm{A}$, correspondían a principales y los de la letra B a los comunes. La muestra de esta aplicación se observa de manera permanente y persistente en muchas de las actuales ciudades de México (Figura 5). 
Figura 5 : Aerofotos de las ciudades de México, Guadalajara y Puebla, respectivamente
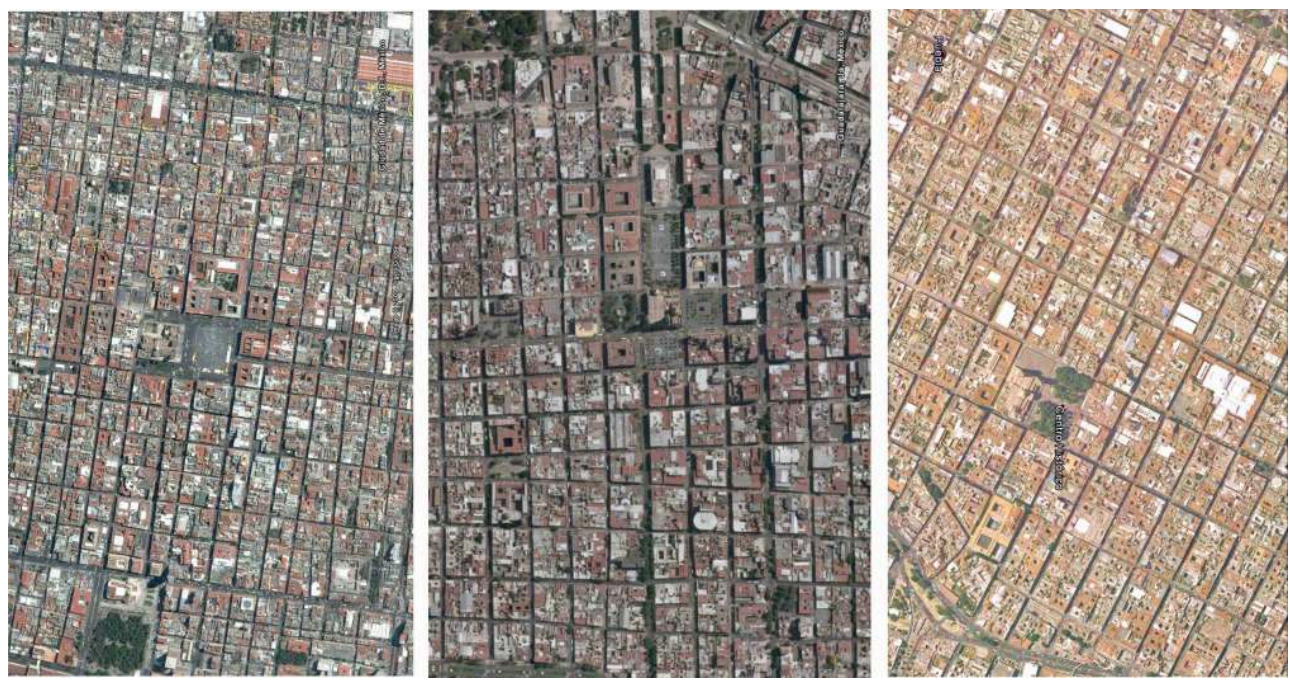

Imágenes tomadas de Google Earth, 2012

20 Ejemplos como las ciudades de México, Guadalajara, Puebla, Mérida, San Luis Potosí y otras más, dan cuenta de la aplicación de esa visión convertida en ordenanza y que necesariamente serían referentes de lo que se concibe como una Villa o Ciudad Novohispana.

21 Sin embargo, en la Villa de la Aguas Calientes la condición no fue la misma por las razones mencionadas acerca de su difícil crecimiento -abandono y repoblación-, condición de quebrantamiento de la aplicación estricta de la ordenanza pero sin olvidar los urbemas que prevalecían, que permanecieron durante bastante tiempo y que se observan presentes de alguna manera, buscados en la construcción urbanoarquitectónica de la ciudad (Figura 6). 
Figura 6: Aerofoto de la ciudad de Aguascalientes

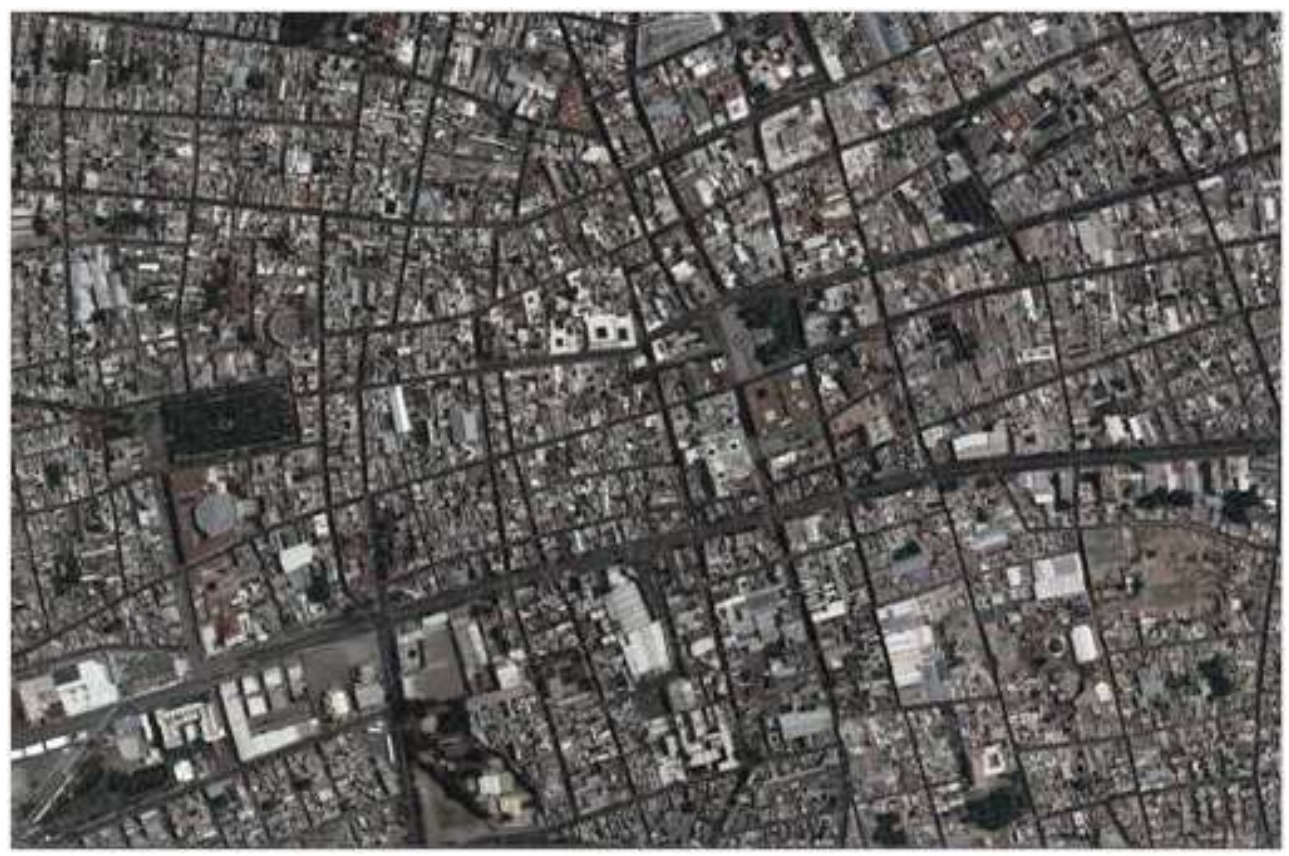

Imagen tomada de Google Earth, 2013

Bajo esta circunstancia, a nuestro cartógrafo/pintor en cuestión se le impuso esta ortogonalidad como una "de las categorías cognitivas construidas socialmente", con la consecuente “... subjetividad y reflexibilidad en los datos visuales..."; así es explicable el “...posicionamiento y la intencionalidad del autor...", alejado de la realidad de que la organización del espacio y la traza sólo serían perceptibles desde gran altura, por lo que su interpretación, al menos como la entendemos, introdujo su propia sensación subjetiva de panopticidad, misma que será analizada infra.

Una parte de esta imagen en cuestión es la representación del "arrabal" de indios de San Marcos, de donde se puede colegir también esa condición de subjetividad y reflexibilidad (Figura No. 7). 
Figura 7: Detalle de la imagen del Pueblo/Barrio de San Marcos, adyacente a la Villa de españoles de las Aguas Calientes

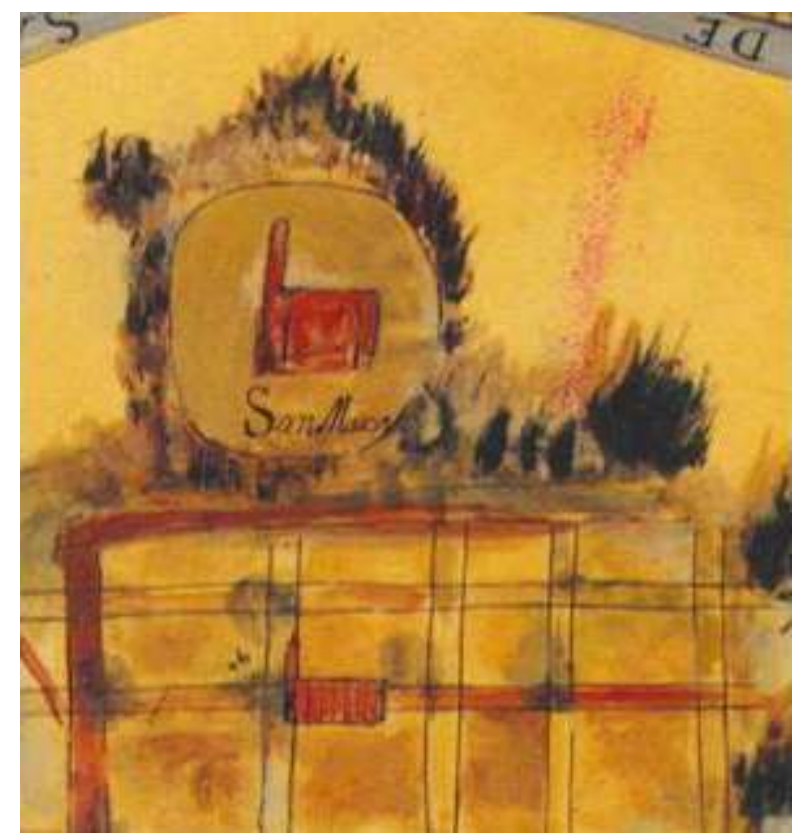

Fuente: Archivo Histórico del Estado de Aguascalientes, Fototeca, No. Cat. 008 con la imagen más lejana que de la villa se conoce en el tiempo, que es la pintura antes referida, presuntamente del primer tercio del siglo XVIII (Figura 8), podemos advertir la distancia entre lo prescrito y lo realmente ejecutado. ${ }^{19}$ Dicha imagen, de la que se puede consultar una fotografía del original en el Archivo Histórico del Estado de Aguascalientes (AHEA) y cuyas medidas son $22 \times 15 \mathrm{cms}$, con el número de catálogo 008, sin escala y sin datos del autor pero fechada en 1730, obra en el Archivo Histórico del Arzobispado de Guadalajara (AHAG). Por supuesto, dicha imagen la debemos considerar con cautela debido a que no es una representación "objetiva", sino que se trata de una imagen idealizada de la traza. Aun así, vale la pena describirla porque más allá de las 
licencias pictográficas de su autor, proporciona valiosos elementos para confirmar su datación y para poder hacer algunas inferencias mediante el análisis visual.

Figura 8: Fracción del territorio donde se situaba la Villa de Aguascalientes y el pueblo de San Marcos. 1730

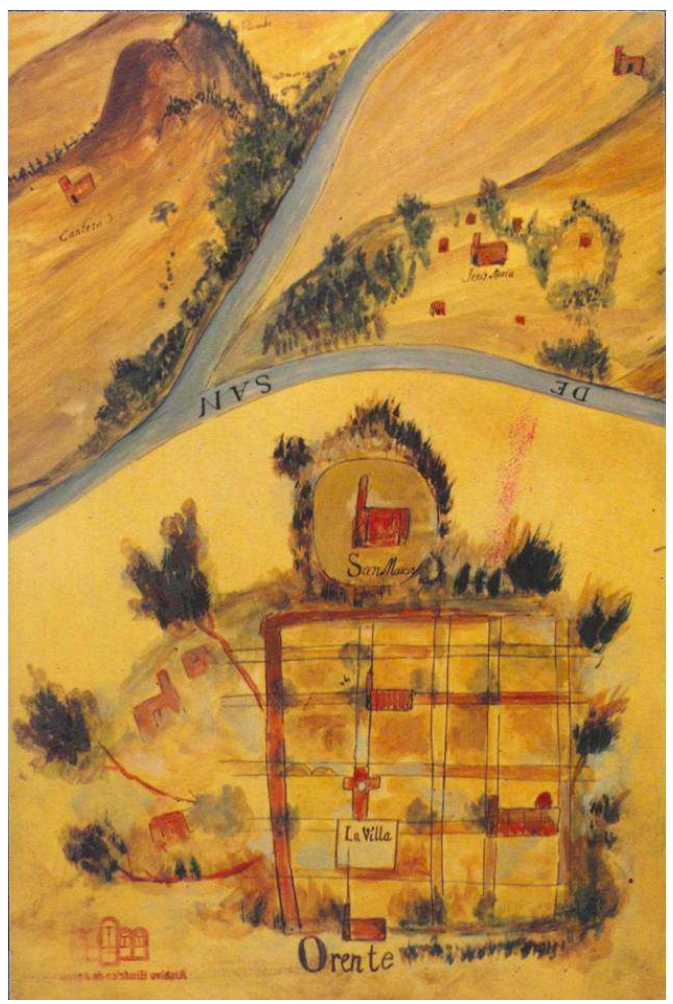

Fuente: Archivo Histórico del Estado de Aguascalientes. Fototeca. No. Cat. 008

La imagen presenta la traza de la villa de Aguascalientes y sus alrededores inmediatos. ${ }^{20}$ Al poniente se ven: el Picacho (los "pies" del Cerro del Muerto, un elemento topográfico muy señalado del paisaje natural y cultural de los aguascalentenses) y el casco o la iglesia de la hacienda de La Cantera, que el 2 de abril de 1674 el bachiller don Diego de Quijas Escalante compró a Doña Gertrudis de los Cobos y Vera. ${ }^{21}$ Con una iglesia y su torre en alzado se señala la ubicación del cercano pueblo de indios de Jesús María (cuyo templo fue comenzado en 1728-30 y concluido en 1750), ${ }^{22}$ en una localización geográfica imposible y que sólo es entendible en el contexto de la probable intención de su autor de mostrar una panorámica de los principales sitios que circundaban la villa, sin consideración alguna de escala ni "posición real”, pues sólo es una representación pictográfica y no planimétrica; a su alrededor se observan algunas casas, una de las cuales aparece rodeada de un vergel; en el ángulo superior derecho está pintada una edificación con torre o garitón en alzado, casi a la vera de un camino que suponemos era el que iba para la capital de la Nueva Galicia, Guadalajara, pero es difícil determinar a qué población se refería el autor, dadas las convenciones antes citadas (¿o se tratará de San José de Gracia, el otro pueblo de indios de la jurisdicción de Aguascalientes?). Se aprecian dos cursos de agua, uno con toda seguridad es el del río San Pedro, que cruza de norte a sur dicha jurisdicción; el otro probablemente sea el arroyo del Cedazo. El arroyo de los Adoberos sólo lo adivinamos por conocer su curso, pero no es visible en la imagen (vid infra). 
Pero lo más interesante, para nuestros propósitos, es la traza de la villa misma, que aparece resuelta en un rectángulo casi cuadrado, al interior del cual se presenta un viario reticular conformado por cinco calles en el sentido oriente-poniente, una de las cuales suponemos que es el arroyo de Los Adoberos, curiosamente pintado como si la calle estuviese sobrepuesta al arroyo; y siete calles en el sentido norte-sur, de las que una apenas aparece sugerida con una línea indicativa del lindero oriental de la misma; el cruce ortogonal de todas estas calles produce un parcelado conformado por 24 manzanas de diferentes tamaños, con formas cuadradas y rectangulares. Se distinguen varios elementos importantes en la imagen: el cuadrilongo de la plaza principal, en donde aparece la leyenda "La Villa"; la planta de una iglesia (la única así representada) que, por su disposición en cruz latina corresponde a la Parroquia, adyacente a la plaza; de una de las calles que salen de esta última, hacia el norte (que correspondería a la calle de Tacuba), se llega a una construcción en alzado, sin torre, que debe representar la iglesia y convento de San Diego, que por cierto en el siglo XVII todavía estaba a "extramuros" de la villa (si bien, su posición en la imagen no es cartográficamente "correcta"); en el límite más oriental, alineada con una de las calles que salen de la plaza (la de Ojocaliente, más tarde llamada del Centenario), se muestra el alzado de otra iglesia, con su torre, que suponemos tendría que ser la de la capilla anterior del convento de San Juan de Dios, aunque geográficamente esta ubicación es también incorrecta; en el sentido contrario, hacia el poniente de la plaza, sobre la calle que fue de San Sebastián (o de la Merced), se ve el alzado de otra iglesia y su torre, que no puede ser otra que la del convento de La Merced, pero probablemente alguna capilla anterior a la que hoy conocemos.

29 Y por último, fuera de la traza antes descrita, se ven cuatro elementos muy notorios: en la parte inferior izquierda de la imagen se aprecia una edificación no identificada, que podría pensarse que fuese la iglesia inconclusa del Señor de la Salud, en el barrio del mismo nombre, pero esta construcción es del siglo XIX, por lo cual proponemos tres posibilidades: o se trata de un ícono que sustituye al barrio mismo (improbable), o bien representa el panteón del lugar (o quizá a su capilla, anterior al templo actual), abierto desde finales del siglo XVIII, o, en fin, es una marca indicadora de que allí se desarrollaba un culto específico. Un poco más arriba se observa el alzado de algo que parece otra construcción con torre, por lo que puede tratarse de alguna ermita o lugar de devoción de los pobladores del Barrio de Triana (la capilla anterior al actual templo del Señor del Encino, y este mismo, son posteriores a la realización de esta cartografía pictórica), en una localización sólo indicativa de la existencia de edificaciones al otro lado del arroyo, ${ }^{23}$ la última imagen de esta parte de la pintura tampoco es completamente reconocible, pero creemos que se puede tratar de un ícono que señalaría el panteón de San Marcos o bien su capilla.

Como vimos previamente, a la parte del poniente de la villa y a extramuros de ella, se destaca claramente, con la leyenda "San Marcos", el barrio de indios con su respectiva iglesia dedicada a la Limpia Concepción (aunque la torre que conocemos hoy, en ese entonces todavía no se levantaba, lo que ocurrió entre 1763 y 1765), ${ }^{24}$ asentamiento que aparece encerrado en un vergel circundante que suponemos representa los límites del arrabal o "pueblo de San Marcos". ${ }^{25}$ Creemos que los íconos con que se representan las edificaciones religiosas son una mera convención que sólo indica la ubicación de aquéllas en el terreno, cosa que confirmamos al advertir la forma estandarizada y no individualizada con que se los presenta (con excepción de San Diego y la Parroquia). 
31 Varios comentarios merece esta imagen, el primero de ellos es el de la fecha de su realización. Si juzgásemos por los elementos arquitectónicos que en ella aparecen, debemos dar por seguro que es anterior al año en que comenzó a edificarse el Santuario de Guadalupe (1769), ${ }^{26}$ puesto que no aparece en la pintura, pero no anterior a 1727 , dado que ya se encuentra representada la iglesia del pueblo de San Marcos, iniciada precisamente en ese año; ${ }^{27}$ y aunque se muestra una edificación por el área de Triana en una zona imposible (vid infra), creemos, como dijimos supra, que ésta podría representar una huella o marca del culto que por tradición oral se dice se dispensaba al arcángel San Miguel, y no la que hoy conocemos, levantada entre 1773 y $1796,{ }^{28}$ es decir, posterior a la fecha clave de la erección de Guadalupe, ni tampoco la anterior, construida entre 1761 y $1764 .^{29}$ Otra clave es la parroquia, que aunque su fábrica comenzó en 1704, veintitrés años antes que la iglesia del pueblo de San Marcos (que es nuestra clave crítica), para 1738 ya estaba prácticamente terminada, circunstancia revelada por su figuración en cruz. De lo anterior refrendamos la noticia de que en una fecha cercana a 1730, o en tal año preciso, se realizó esta imagen pictórica, ya que no puede ser anterior a 1727 ni posterior a 1769; desde luego, ya existían para entonces los conventos de San Diego (1661-1682); ${ }^{30}$ la Merced (1665-1773, este último año, el de la erección de su torre) y San Juan de Dios (1685-1772, año, el último, en que se levantó la torre). ${ }^{31}$

La iglesia de La Merced y la iglesia de San Juan de Dios (después llamada de San José), las iglesias de San Marcos y El Encino (casos en los que hay evidencia documental de capillas anteriores), ${ }^{32}$ así como Guadalupe, Tercera Orden y San Juan Nepomuceno ${ }^{33}$ todas con sus respectivas torres (salvo el santuario guadalupano)-, son edificaciones de la segunda mitad del siglo XVIII, de ahí sus filiaciones estilísticas; la Parroquia es de la primera mitad del XVIII, que también contó con dos capillas anteriores, ${ }^{34}$ y San Diego del siglo XVII (edificado sin torre, por prescripción de las constituciones franciscanas).

Así que aquí tenemos una de dos opciones a falsear: a) los íconos de las iglesias representadas son los del siglo XVIII, cosa que un historiador poco escrupuloso se vería tentado a aseverar; b) los íconos son de las capillas o edificaciones religiosas anteriores, o incluso simplemente marcas de un culto específico. Ante la falta de más datos, por ahora tendremos que suponer como más probable la segunda opción, de acuerdo con lo expuesto dos párrafos arriba.

\section{La invención del territorio como problema historiográfico: la Villa de Aguas Calientes y sus alrededores}

Cualquiera sea la solución a esta conjetura, reafirmamos que la intención del autor no fue elaborar un mapa o plano cartográfico de la villa y sus alrededores, sino presentar un "esquema" idealizado de su traza, en el que sin embargo puede apreciarse una indudable voluntad de conjugar en una sola imagen la organización prescrita en las Ordenanzas de Población y la estructuración "parroquial" del espacio urbano, pues de todos los edificios y sectores de la villa representados, incluyendo el Barrio de San Marcos y los extramuros inmediatos, al menos seis corresponden a construcciones eclesiásticas (de las cuales tres de ellas pertenecían a otras tantas órdenes religiosas) y dos son de carácter civil. Podemos darnos una idea del peso específico de la institución 
del clero regular en la villa de Aguascalientes si la ponemos en perspectiva junto a otra ciudad novohispana contemporánea: Querétaro, la tercera ciudad de Nueva España por el número de habitantes, probablemente más de 5,000 , poseía seis conventos a mediados del XVII, ${ }^{35}$ lo que significa una proporción de un convento por cada 833 hab. La villa de Aguascalientes contaba, para la misma época, con 3 conventos de religiosos y una población de 764 habitantes, ${ }^{36}$ para una proporción de 255 hab. por cada convento; en magnitudes absolutas, aparentemente la primera ciudad presentaba una cobertura mayor, si es que (y no es el caso) considerásemos a dicha cobertura con los criterios de una normatividad promedio contemporánea, pero si ponemos la relación en magnitudes relativas, los conventos queretanos apenas si representaban un $0.12 \%$ con respecto a la población, mientras que los de la villa de Aguascalientes representaban un $0.39 \%$, lo que da una idea de la densidad o peso específico de los establecimientos conventuales. No sabemos por el momento qué tanto dicho porcentaje se modificó a la baja o a la alta después de 1730, fecha en que está datada la cartografía pictórica.

Tenemos entonces una superposición de dos órdenes: uno civil, laico, y otro clerical, integrados en una sola composición pictórica (Figura 9). Dos "urbanismos armonizados" están presentes: el de la ciudad-concepto, producto del afán normativo, y el de la ciudad-metáfora, relacionado con las distribuciones simbólicas (parroquiales), tanto en su vertiente identitaria como eclesial-administrativa.

Figura 9. Superposición digital de la cartografía pictórica (sin escala) en la traza actual de Aguascalientes, con la intención de mostrar la diferencia entre la traza «ideal» y la «real»

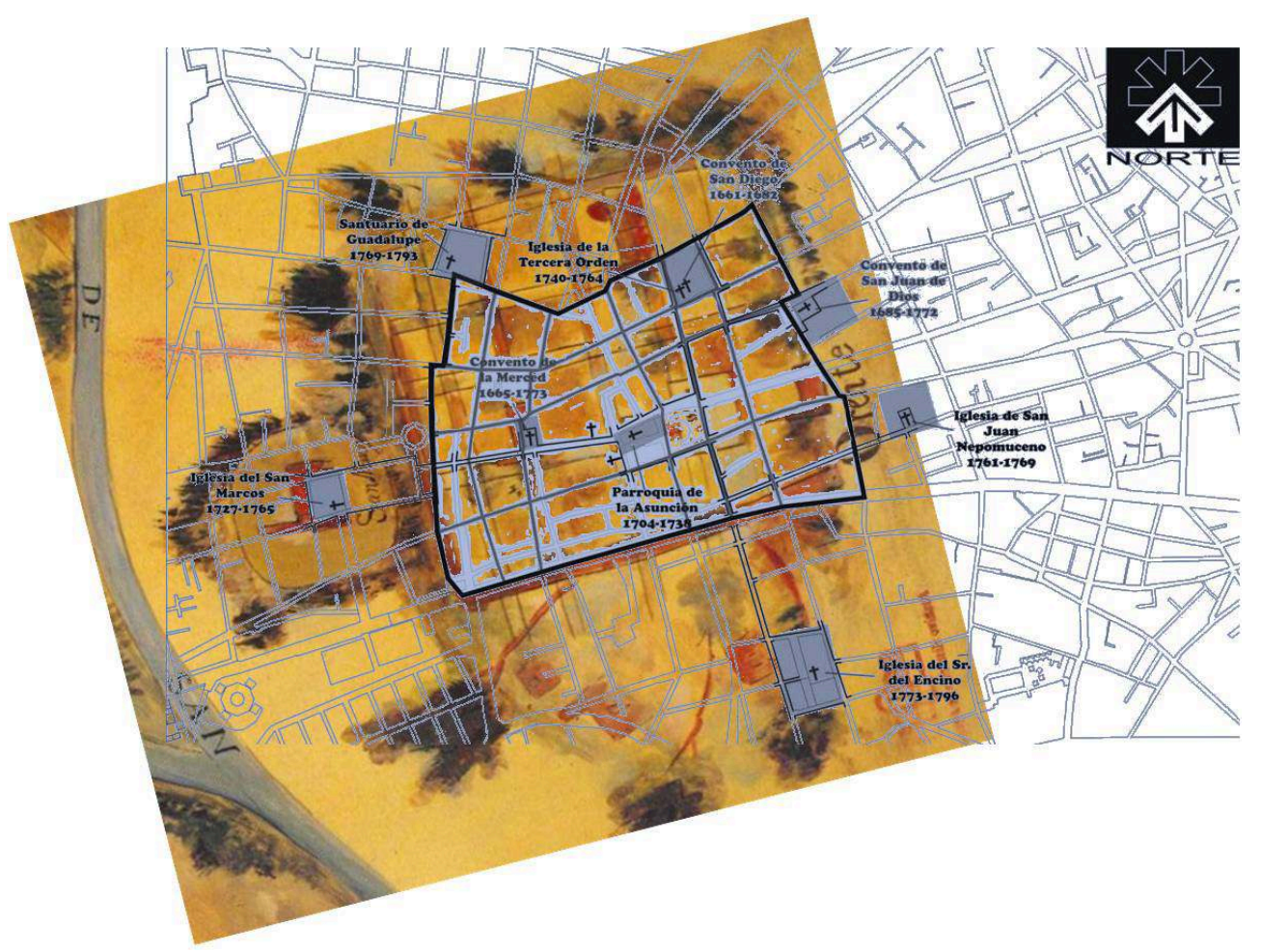

Fuente: elaboración propia con base en la cartografía histórica y contemporánea. Tratamiento digital de Eduwiges Hernández Becerra

Entre ambos, el urbanismo práctico, el de la ciudad-experiencia, el de la cotidianidad urbana, no visible en la ilustración, nos remite a una imagen diferente, tal como lo muestran los documentos. El contraste entre la villa idealizada y la ciudad "real" es 
evidente, como puede colegirse de la graficación de la cartografía pictórica siguiendo las huellas de la traza actual. La traza resultante, tensada entre los extremos de las "tácticas del caminante" y las estrategias de rentabilización del suelo, se rebela a la idealización normativa pero no deja de regirse por parcelaciones simbólico-religiosas comúnmente señaladas por un centro y distribuciones cardinales (en forma de aspa o cruz), de diversos establecimientos religiosos, como una estructura subyacente que se superpone a las anteriores (Figura 10), que va jalonando y alterando el urbanismo racional de las prescripciones normativas, pero que, sin embargo, está ahí, tan "real" como la otra, al menos desde la cotidianeidad de las personas. Este fenómeno es lo que Eduardo López Moreno denomina "la cruz urbana", que rigió para la ciudad de Guadalajara hasta el siglo XVIII, y que tuvo consecuencias para la traza, pues

Este tipo de crecimiento se hace a través de una racionalidad que testimonia una reflexión religiosa subyacente, que muestra una lógica edilicia bastante elaborada y un conjunto de técnicas apoyadas en el conocimiento de la geometría; lo sagrado y lo religioso son, durante este periodo, los grandes ordenadores del espacio urbano, así como también los grandes "desordenadores" de la traza reticular, puesto que la materialización del discurso religioso da lugar a un modelo urbanístico diferente al de la cuadrícula. ${ }^{37}$

Figura 10: Estructura parroquial de los siglos XVII-XVIII de la Villa de Aguascalientes, sobrepuesta sobre el trazado actual de la ciudad

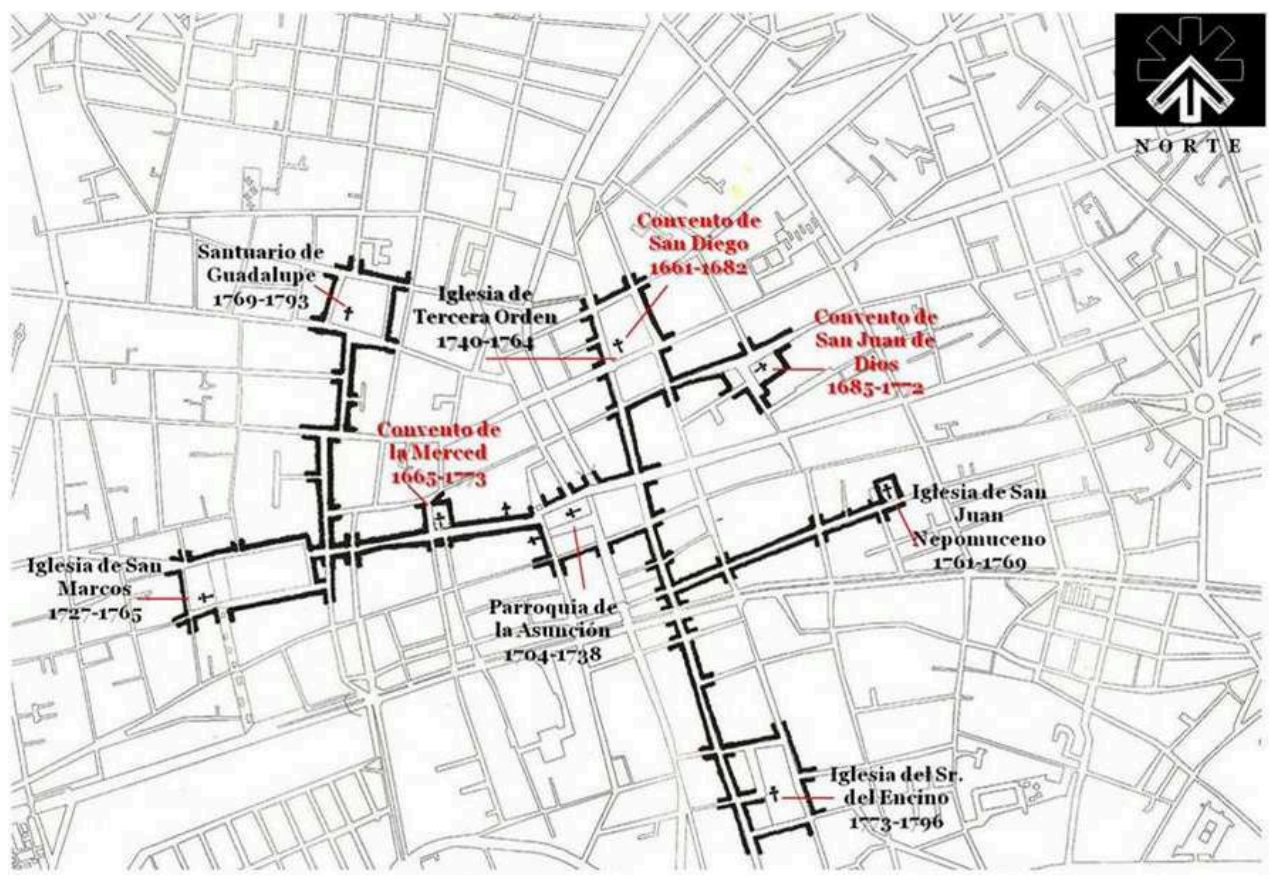

Fuente: elaboración propia. Tratamiento digital: Eduwiges Hernández Becerra

Escapan a las pretensiones de este artículo las razones que el autor tuvo para presentar aquella imagen idealizada de la traza, por lo que sólo podemos especular a partir de lo que muestra. En este sentido, es significativo que el pintor haya representado preferentemente edificaciones del dominio sagrado y aquel soporte sobre el que las primeras se desplantan, que pertenece al dominio terrenal, es decir, el suelo, cuyo control, al menos en el papel, era motivo de intensa preocupación por las autoridades virreinales $\mathrm{y}$, a contrapelo, de intenso acaparamiento por diocesanos y regulares. ${ }^{38}$ 
39 Al respecto de las convenciones iconográficas virreinales, Raquel Urroz señala que A. Russo, al estudiar el "encuentro" de las convenciones pictórico-cartográficas hispanas e indígenas, refiere algunas nociones que ya existían tanto en la plástica europea como en la indígena y que continuaron representándose cartográficamente. Por ejemplo, la estrecha relación entre el tiempo y el espacio, la no separación de naturaleza sagrada y humanidad o la tensión entre religiosidad y el poder económico representado en la tierra. $^{39}$

Si acaso nuestro artista fue español, criollo o incluso mestizo, no dejó de plasmar en su cuadro las convenciones iconográficas predominantes en la época para el caso de representaciones que en rigor no eran mapas planimétricos escalados, y a su manera construyó su propia interpretación de la villa, pues, como dice A. Russo, "el dibujo de un territorio inventa también el territorio" ${ }^{40}$ es decir, crea algo subjetivamente ligado a la relación histórica entre el artista y el paisaje ${ }^{41}$ de manera parcialmente atemporal o, si se quiere, antiespacial. Sin duda, como apunta Martha Fernández, la percepción no era la misma entre quienes padecían las ciudades y villas y quienes, aun viviendo en ellas, podían gozarlas por sus mejores condiciones de vida, reflejando lo anterior en "representaciones gráficas y escritas" 42 que no eran ni inocentes ni neutrales, sino cargadas con todo el subjetivismo de su particular situación. Comenta esta autora que "las diversas imágenes que nos ofrecen cronistas y pintores son representaciones idealizadas", es decir, en ellas hay toda una construcción imaginal. ${ }^{43}$

41 Como sugiere Russo, la cartografía pictórica novohispana parece haber sido concebido desde "dentro", desde la propia afectividad del pintor, pues para entender estas convenciones "desde el exterior", se deben girar sus elementos paisajísticos y arquitectónicos "incesantemente, o uno mismo alrededor de ellos, para abarcar visualmente toda la superficie representada" ${ }^{44}$ en un movimiento circular propio de la concepción indígena del tiempo, que sumado al geometrismo ficticio de la traza, que no puede provenir más que de las "modalidades occidentales de representación del espacio", ${ }^{45}$ produce lo que Russo denomina el "realismo circular" de la cartografía novohispana, que es una manera de luchar contra el "no-lugar". ${ }^{46}$

Requeriríamos de más información histórica acerca del pintor para inferir con mayor certeza las posibles motivaciones que lo movieron, pero partiendo de la propia imagen vemos cómo los hallazgos de Russo se ven aquí confirmados: la manera de resolver iconográficamente el paisaje circundante, con sus cerros, cursos de agua y formaciones arbóreas, contrastan (multiplicidad) pero a la vez responden a las mismas convenciones pictóricas (coherencia) de las edificaciones urbanas (representadas de forma muy semejante en la campiña) y de la traza misma; todos estos elementos, juntos, subrayan justamente la construcción de un lugar central, un "ombligo del mundo", un axis mundi, en el que ha tomado asiento la cruz como símbolo de la sacralización del territorio y de la subordinación del paisaje a él (Figura11), pues tanto la zona urbana como todo aquello a extramuros y allende sus fronteras, se somete al gobierno del orden sacro representado por la cruz urbana (ver Figura9), reordenando en la concepción del pintor-cartógrafo aquello que los procesos ligados a la propiedad del suelo urbano obligaban a ajustar en la práctica; de ahí el resultado, en la traza parroquial "real", de la cruz urbana en forma más bien de aspa (ver Figura10). 
Figura 11. Cartografía pictórica de la jurisdicción parroquial de Aguascalientes. 1730

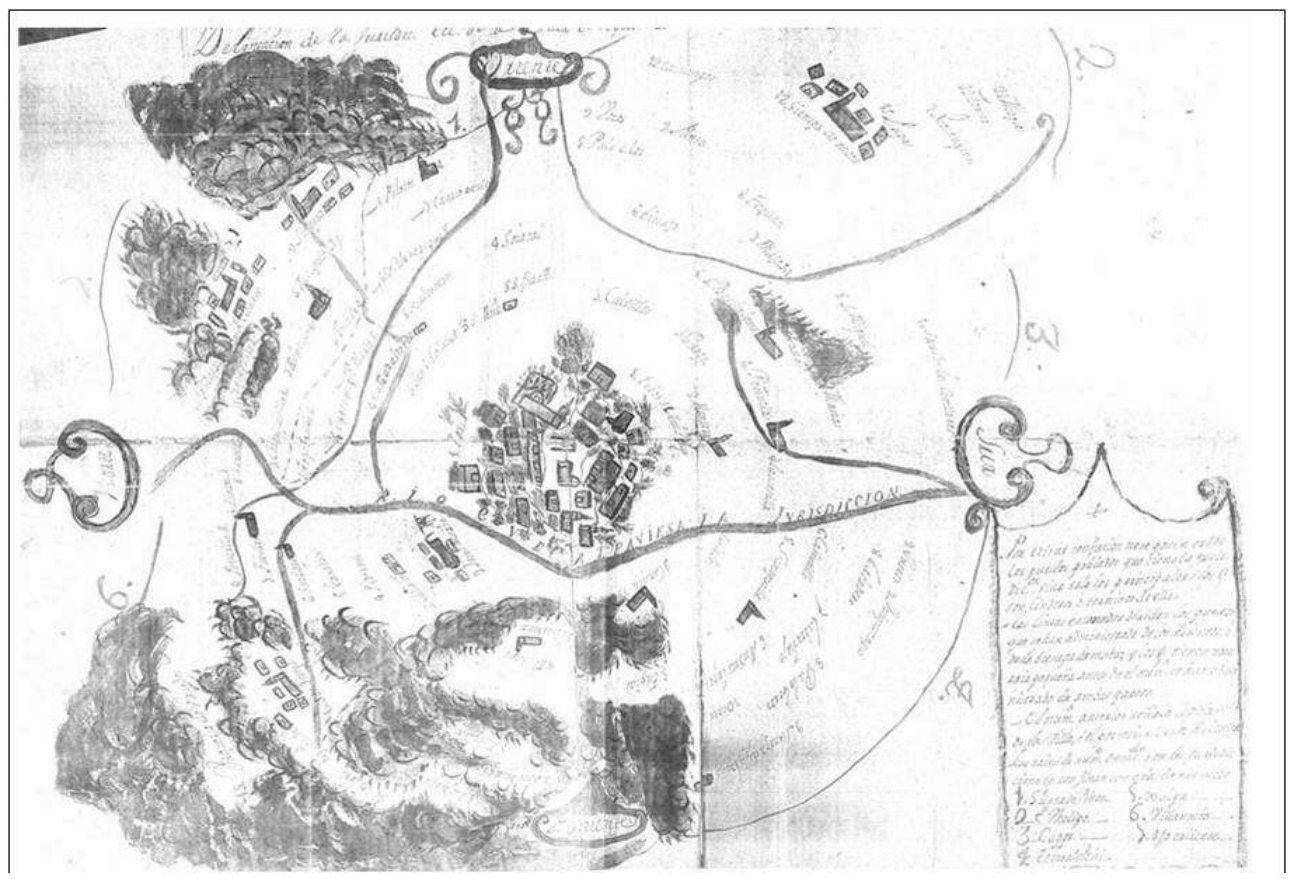

FUENTE: FOTOgRAFÍA DIgITALIZADA DEL ORIgINAL. ARCHIVO HISTÓRICO DEL ESTADO DE AgUASCALIENTES, MAPOTECA, NO. CAT. 009

\section{Comentario final}

En primer lugar, el análisis de la cartografía pictórica de la villa de Aguascalientes arroja la confirmación del año de su creación (1730). Y decimos bien, su creación, porque al tratarse de una visión idealizada de un paisaje territorial en el que está inserta la villa, incorpora la propia concepción subjetiva que del mismo tuvo el pintor-cartógrafo, conformando con ello una genuina invención que sigue las convenciones iconográficas de su tiempo, entre las que la multiplicidad infinita y la coherencia interna constituyen dos aspectos cruciales de la representación cartográfica novohispana, confirmando con esto la interpretación de Alessandra Russo. Por esta razón, en la cartografía pictórica de Aguascalientes aparecen con escasa o nula relación de escala y de ubicación cartesiana precisa, elementos tan dispares como ríos, arroyos, edificios religiosos, poblaciones cercanas, calles, traza urbana, resueltos en estrategias coloristas de filiación nativa para el caso del paisaje y en figuraciones cuasi-ortogonales de tradición renacentista para el caso de los edificios y la traza urbana; es decir, todos los distintos urbemas que al pasar por el filtro de la subjetividad del autor contribuyeron a crear su propia fábula o narrativa como lector in urbis, al reordenar el espacio conforme a un símbolo sacro, que de otro modo ciertamente subsistía, si bien distorsionado por los linderos de la traza pragmática, sujeta a las irregularidades geométricas y jurídicas de los predios urbanos.

Las "imprecisiones", pues, no obedecen a incorrecciones cartográficas, sino probablemente a la necesidad que el pintor-cartógrafo tenía de dar a entender otra cosa: crear un lugar en el que quedase establecido el imperio de la cruz como símbolo de una tierra cristianizada, como marca de un territorio sacralizado, de un orden sagrado que somete los prosaicos parcelamientos del urbanismo pragmático y las 
prescripciones del urbanismo normativo, a la estructura parroquial del urbanismo simbólico.

Por otro lado, la utilidad de esta fuente sólo puede revelarse en su completa riqueza siempre que como historiadores sepamos echar mano de otras ciencias y procedimientos auxiliares de la disciplina histórica, tales como la epistemología, el análisis y lectura hermenéuticas de la imagen, la cartografía como ciencia del estudio y elaboración de los mapas geográficos, el urbanismo y la arquitectura, así como de los medios proporcionados por las computadoras y las tecnologías de la información y la comunicación (TIC) para el análisis visual y textual.

Si juzgásemos por lo que aparece en esta cartografía pictórica, tendríamos que concluir que se trata de un "mapa" híbrido entre el tipo de las Relaciones Geográficas, que la administración virreinal ordenaba para la representación de "paisajes urbanos", y el tipo de "mapa de mercedes", que según Alessandra Russo representaba la configuración del paisaje provinciano; ${ }^{47}$ en él encontramos conjugadas algunas convenciones pictóricas indígenas, renacentistas y hasta barrocas, por lo que, apoyados en los estudios de esta última autora, nos vemos tentados a hipotizar que esta cartografía pictórica probablemente fue elaborada por un cartógrafo-pintor de origen o al menos de ascendencia indígena (mestizo), o si no, de origen peninsular pero familiarizado con las convenciones nativas, todo lo cual se demuestra por su panopticidad centrípeta.

\section{BIBLIOGRAFÍA}

Bielza de Ory, Vicente (2002), "De la ciudad ortogonal aragonesa a la ciudad cuadricular hispanoamericana como proceso de innovación-difusión, condicionado por la utopía”, en Scripta Nova. Revista electrónica de geografía y ciencias sociales, Universidad de Barcelona, Vol. VI, No. 106, 15 de enero, en: «http://www.ub.es/geocrit/sn/sn-106.htm».

Brea, José Luis (2007), “Cambio de régimen escópico: del inconsciente óptico a la e-image”. Estudios Visuales, No. 4, pp. 146-164.

Chávez Aranda, José Humberto (2010), Del mito al rito de El Señor del Encino. Talleres de Ediciones Chávez Aranda, Guadalajara.

Corpus Alonso, Ricardo, Pbro. (1969), La Catedral y su Cabildo. Edición del autor, Aguascalientes.

Fernández, Martha (2009), “De puertas adentro: la casa habitación”, en Antonio Rubial García (Coord.) "II. La ciudad barroca”, en Pilar Gonzalbo Aizpuru (Directora). Historia de la vida cotidiana en México. El Colegio de México-Fondo de Cultura Económica, México.

Fernández Christlieb, Federico y Urquijo, Pedro S. (2006), "Los espacios del pueblo de indios tras el proceso de Congregación, 1550-1625”, en Investigaciones Geográficas. Boletín del Instituto de Geografía, No. 60, UNAM, pp. 145-158.

García Martínez, Bernardo (2002), "La ordenanza del marqués de Falces del 26 de mayo de 1567: Una pequeña gran confusión documental e historiográfica”, en Jahrbuch für Geschichte Lateinamerikas, No. 39, pp. 163-191. 
Gutiérrez, José Antonio (1999), Historia de la Iglesia Católica en Aguascalientes, Vol. 1, Parroquia de la Asunción de Aguascalientes. Universidad Autónoma de Aguascalientes-Obispado de Aguascalientes-Universidad de Guadalajara, México.

Gutiérrez, José Antonio (2003), Historia de la Iglesia Católica en Aguascalientes, Vol. II. Obispado de Aguascalientes-Universidad Autónoma de Aguascalientes, México.

Hernández, Rafael (2006), “Argumentos para una epistemología del dato visual”. Cinta de Moebio, No. 26, pp. 196-206.

La Recopilación de las Leyes de los Reynos de las Indias (1680), en: «http://www.gabrielbernat.es/ espana/leyes/rldi/indice/indice.html».

López Moreno, Eduardo (2001) La cuadrícula en el desarrollo de la ciudad hispanoamericana. Guadalajara, México. Universidad de Guadalajara-Instituto Tecnológico de Estudios Superiores de Occidente, 2da. edición, México.

Mangieri, Rocco (2001), "Lector in urbis: espacio urbano y estrategias narrativas", en Las fronteras del texto. Miradas semióticas y objetos significantes. Universidad de Murcia, España.

Ochoa V., Fray Ángel S. (1953), Breve historia de la Purísima de San Diego de Aguascalientes. Gobierno Eclesiástico del Obispado de Aguascalientes, Aguascalientes.

Russo, Alessandra (2005), El realismo circular. Tierras, espacios y paisajes de la cartografía novohispana, siglos XVI y XVII. IIE-UNAM, México.

(2007), "Caminando sobre la tierra, de nuevo desconocida, toda cambiada", en Terra Brasilis [on line], 7-8-9, en: «http://terrabrasilis.revues.org/388», consultado el 29 de abril de 2013.

Sánchez Santiró, Ernest (2004), “El nuevo orden parroquial de la ciudad de México: población, etnia y territorio (1768-1777)”, en Estudios Históricos Novohispanos, No. 30, enero-junio, pp. 63-92. Urroz, Raquel (2009), Reseña del libro de Alessandra Russo, El realismo circular. Tierras, espacios y paisajes de la cartografía novohispana, siglos XVI y XVII, en Investigaciones Geográficas, Boletín 68, pp. 131-134.

Viforcos Marinas, Ma. Isabel (2009), "La ciudad hispanoamericana: reflexiones en clave de poder”, en: «http://www.moderna1.ih.csic.es/cordoba/la_ciudad_hispanoamericana.pdf».

Wright Carr, David Ch. (1989/1994/2006), “La vida cotidiana en Querétaro durante la época Barroca", Estudios sobre las culturas de México, capítulo publicado en el libro Querétaro ciudad barroca, Querétaro, Secretaría de Cultura y Bienestar Social, Gobierno del Estado de Querétaro, versión electrónica, en: «http://www.paginasprodigy.com/dcwright/vida.htm, consultado el 10 de abril de 2013».

\section{ANEXOS}

\section{Archivos consultados}

AGMA- Archivo General Municipal de Aguascalientes, Fondos Especiales, Sección Zacatecas.

AHEA- Archivo Histórico del Estado de Aguascalientes), Mapoteca.

AHEZ- Archivo Histórico del Estado de Zacatecas, Fondo Notarías. 


\section{Figuras}

\begin{tabular}{|c|c|c|}
\hline Título & Leyenda & Créditos \\
\hline $\begin{array}{l}\text { Figura } \\
1\end{array}$ & $\begin{array}{l}\text { Localización de la ciudad de Aguascalientes en } \\
\text { la República Mexicana }\end{array}$ & $\begin{array}{l}\text { «http://www.map.mx/img/upload/ } \\
\text { mexico-cia-factbook-map.png» }\end{array}$ \\
\hline $\begin{array}{l}\text { Figura } \\
2\end{array}$ & Asentamiento de Santa Fe, Granada, España & Google Earth, 2011 \\
\hline $\begin{array}{l}\text { Figura } \\
3\end{array}$ & $\begin{array}{l}\text { Sección de la Cédula de Felipe II acerca de los } \\
\text { usos, costumbres y disposiciones sobre las } \\
\text { Indias y de su población }\end{array}$ & $\begin{array}{l}\text { «http://www.gabrielbernat.es/espana/ } \\
\text { leyes/rldi/indice/indice.html» }\end{array}$ \\
\hline $\begin{array}{l}\text { Figura } \\
4\end{array}$ & $\begin{array}{l}\text { Propuesta hipotética para un nuevo } \\
\text { asentamiento }\end{array}$ & $\begin{array}{l}\text { Federico Fernández Christlieb y Pedro S. } \\
\text { Urquijo (2006, p. 53) }\end{array}$ \\
\hline $\begin{array}{l}\text { Figura } \\
5\end{array}$ & $\begin{array}{l}\text { Aerofotos de las ciudades de México, } \\
\text { Guadalajara y Puebla, respectivamente }\end{array}$ & Google Earth, 2012 \\
\hline $\begin{array}{l}\text { Figura } \\
6\end{array}$ & Aerofoto de la ciudad de Aguascalientes & Google Earth, 2013 \\
\hline $\begin{array}{l}\text { Figura } \\
7\end{array}$ & $\begin{array}{l}\text { Detalle de la imagen del Pueblo/Barrio de San } \\
\text { Marcos, adyacente a la Villa de españoles de } \\
\text { las Aguas Calientes. }\end{array}$ & $\begin{array}{l}\text { Archivo Histórico del Estado de } \\
\text { Aguascalientes, Fototeca, No. Cat. } 008 .\end{array}$ \\
\hline $\begin{array}{l}\text { Figura } \\
8\end{array}$ & $\begin{array}{l}\text { Fracción del territorio donde se situaba la Villa } \\
\text { de Aguascalientes y el pueblo de San Marcos, } \\
1730\end{array}$ & $\begin{array}{l}\text { Archivo Histórico del Estado de } \\
\text { Aguascalientes, Fototeca, No. Cat. } 008\end{array}$ \\
\hline $\begin{array}{l}\text { Figura } \\
9\end{array}$ & $\begin{array}{l}\text { Superposición digital de la cartografía } \\
\text { pictórica (sin escala) en la traza actual de } \\
\text { Aguascalientes, con la intención de mostrar la } \\
\text { diferencia entre la "traza ideal" y la "real" }\end{array}$ & $\begin{array}{l}\text { Elaboración propia con base en la } \\
\text { cartografía histórica y contemporánea. } \\
\text { Tratamiento digital de Eduwiges } \\
\text { Hernández Becerra }\end{array}$ \\
\hline $\begin{array}{l}\text { Figura } \\
10\end{array}$ & $\begin{array}{l}\text { Estructura parroquial de los siglos XVII-XVIII } \\
\text { de la Villa de Aguascalientes, sobrepuesta } \\
\text { sobre el trazado actual de la ciudad }\end{array}$ & $\begin{array}{l}\text { Elaboración propia. Tratamiento digital } \\
\text { de Eduwiges Hernández Becerra }\end{array}$ \\
\hline $\begin{array}{l}\text { Figura } \\
11\end{array}$ & $\begin{array}{l}\text { Cartografía pictórica de la jurisdicción } \\
\text { parroquial de Aguascalientes, } 1730\end{array}$ & $\begin{array}{l}\text { Fotografía digitalizada del original. } \\
\text { Archivo Histórico del Estado de } \\
\text { Aguascalientes, Mapoteca, No. Cat. } 009\end{array}$ \\
\hline
\end{tabular}

\section{NOTAS}

1. Matemático, físico, ingeniero y agrimensor alemán que residió en la ciudad de Aguascalientes entre 1852 y 1862.

2. En la lectura de José Antonio Gutiérrez, el Oidor Gaspar de la Fuente habría establecido que las construcciones: "estuvieran congregadas de manera que la traza que ha de guardar [la villa] ha 
de dejar una plaza de 100 varas en cuadro y que en la escuadra frontera a la del sureste la iglesia, y entre una cuadra y otra haya un cuadro de veinte varas en ancho y largo"; no sabemos si se trata de un error tipográfico o así aparece en el original del siglo XVII; ver Gutiérrez, 1999, pp. 113-114 (cursivas nuestras).

3. Y que debemos a la generosidad de Luis Gerardo Cortés, quien amablemente nos proporcionó digitalizado un documento de 1830-1831 que recoge un traslado pedido en el año de 1712 por el capitán Juan Fernández de Palos, Alférez Real de la villa de Aguascalientes, sobre la fundación de la misma y muchos otros asuntos relativos a ella, entre los que destaca el Auto de Gaspar de la Fuente; consultar también AGMA, Fondos Especiales, Sección Zacatecas, Caja 1, Exp. 20, 1830-1831.

4. Interpretación que comparte con nosotros Corpus, 1969, p. 16 (cursivas nuestras).

5. Cfr. Gutiérrez, 1999, p. 142. En la misma página, Gutiérrez sugiere que consta en documentos que hacia 1609 el Br. Tomás Ruiz, párroco de la villa, gestionó permisos para que el templo parroquial "ocupara un solar al poniente de la plaza"; sin embargo, una página antes sostiene que el párroco en funciones hacia 1629-33, el Br. Benito de la Canal y Lamadrid, recibió de la Audiencia "un solar al lado oriente de la parroquia que acababa de terminarse", para edificar ahí la casa cural. Estos datos no concuerdan con el sentido literal de la ordenanza de Gaspar de la Fuente, que ubicaría el lugar de la iglesia hacia el ángulo suroeste de la plaza.

6. Viforcos, 2009, p. 33 (cursivas nuestras), en: «http://www.moderna1.ih.csic.es/cordoba/ la_ciudad_hispanoamericana.pdf».

7. Hernández, 2006, p. 198.

8. Hernández, 2006, pp. 200-201.

9. Hernández 2006, p. 201.

10. Hernández, 2006, p. 202.

11. Hernández, 2006, p. 204.

12. Brea, 2007, p. 146.

13. Brea, 2007, p. 148.

14. Por urbema entenderemos aquí el espectro semántico global de un signo, figura o texto urbano determinado (un barrio, una plaza, una avenida, una esquina, un monumento, etc., en términos de los significados que les son atribuidos por las personas). Ver Mangieri, 2001, p. 96.

15. En México se han llevado a cabo tres simposia unificados bajo el título general de "Análisis Visual y Textual Asistido por Computadora" (AVTAC), que han reunido a científicos de las ciencias sociales y las humanidades, así como médicos, arquitectos y otros especialistas de varios países, cuya característica común es el desarrollo de proyectos científicos en sus respectivas áreas de conocimiento, con el apoyo de diversos recursos, procedimientos, aplicaciones y en general software para el análisis computadorizado de imágenes y textos escritos.

16. Sobre este punto, nos parece de enorme actualidad la opinión de Vicente Bielza (2002), quien argumenta que en los diversos estudios sobre el origen de la ciudad hispanoamericana "se echa de menos una reflexión conjunta que utilizando datos históricos, relaciones geográficas de la trama ciudad-territorio con las funciones urbanas e influencia de la ideología nos permita abordar el proceso de innovación-difusión que sigue la ciudad ortogonal, nacida en el medievo europeo y más concretamente en Aragón, como modelo adaptado a las nuevas circunstancias de la colonización española, en ámbitos en que ya había culturas urbanas prehispánicas". Habrá que aclarar, sin embargo, que en el caso de Aguascalientes su fundación no se superpuso a ningún asentamiento indígena.

17. Una parte de la Cédula mencionada dicta: “[...] Por cuanto en mi Consejo Real de las Indias se tiene noticia que el marqués de Falces [...] hizo una ordenanza en 26 de mayo de 1567 por la cual mandó que en los pueblos de indios que necesitasen de tierras para vivir y sembrar se les diesen 500 varas, o las más que hubiesen menester, y que de allí adelante no se hiciese merced a persona alguna de ninguna estancia ni tierras si no fuese pudiéndose asentar 1000 varas de medir paño o 
seda distante y desviada de la población y casas de los indios, y las tierras 500 varas apartadas de dicha población, como ha constado del testimonio de dicha ordenanza que ha llegado al Consejo [...]". Cita tomada del articulo elaborado por Bernardo García Martínez, "La ordenanza del marqués de Falces del 26 de mayo de 1567: Una pequeña gran confusión documental e historiográfica", en Jahrbuch für Geschichte Lateinamerikas, No. 39, 2002, pp. 163-191.

18. Existe discusión en la distancia que debería guardar otro asentamiento, sobre todo español, por el edicto de varias cédulas en fechas distintas, que incluso en su momento fueron motivo de polémica, pleito y corrección.

19. Los planos más remotos de que tengamos conocimiento, y que obran en el Archivo Histórico del Arzobispado de Guadalajara, son dos que datan de 1730, uno de la jurisdicción de la Parroquia de Aguascalientes y el otro de la villa y sus alrededores. Ambos siguen las convenciones pictóricas de la época y son anteriores a la invención de la geometría descriptiva, por lo que en rigor no constituyen una representación cartográfica escalar planimétrica stricto sensu; en estas "cartografías pictóricas" lo representado no tiene intención de fijar posición o ubicación cartesiana ni mostrar su forma "real", sino sólo indicar los elementos presentes en el territorio de una forma indicativa, con íconos que prácticamente actúan como meras marcas o huellas en el terreno, no como puntos regidos por coordenadas.

20. "Plano de la región donde se situaba la Villa de Aguascalientes y el pueblo de San Marcos", fotografía del original, año de 1730, autor no conocido, sin escala, 22 x $15 \mathrm{~cm}$, AHEA, Mapoteca, No. de Catálogo 008.

21. Dicha a hacienda era de labor de trigo, maíz y pan para llevar, de riego y temporal, en la jurisdicción de Aguascalientes, llamada Chapultepec o Chapultepeque, vendida en 4,000 pesos de oro común en reales. Ver Archivo Histórico del Estado de Zacatecas (AHEZ), Fondo Notarías, Fichero 352: 1674-04-02, Felipe Espinosa, Caja: 2 Libro: 7 Foja(s): 10v-12.

22. Ver Gutiérrez, 2003, pp. 488-492.

23. En un trabajo reciente, Chávez Aranda sugiere, apoyado en documentación del Archivo Histórico del Arzobispado de Guadalajara, que en ese tiempo en ocasiones ocurría que a instancias los vecinos se construyeran capillas o ermitas sin licencia canónica, o incluso, a falta de capilla, la festividad de un santo patrón, como era "una costumbre de la época", se hacía mediante altares portátiles, aunque el uso de éstos estaba reservado a las comunidades rurales, condición que conservó el Barrio de La Salud incluso hasta el siglo XX, no así el Barrio de Triana, por lo que para este último caso nos inclinamos por la tercera de las posibilidades antes mencionadas. Ver Chávez, 2010, pp. 57-58 y 75-76.

24. Cfr. Gutiérrez, 1999, pp. 261-263.

25. Gutiérrez, 1999, ha proporcionado documentación contundente que demuestra que el de San Marcos era no más que un arrabal o pueblo, pero no una congrega de indios jurídicamente constituida; ver pp. 123-127, particularmente la p. 125. Aunque no fue el caso de Aguascalientes, por lo dicho antes, la separación política de la república de españoles y la república de indios, sancionada por la legislación hispana del siglo XVI para sus nuevos dominios, se justificaba "en aras tanto de la seguridad de los conquistadores como con base en el objetivo de evangelización de la población indígena", y adquirió forma urbana en la ciudad de México "mediante la delimitación de la traza-inicialmente una superficie de 13 leguas cuadradas- en la parte central de la antigua capital tenochca. Ejecutada mediante calles organizadas ortogonalmente por Alonso García Bravo, en 1521, esta área se reservó para la población española, toda vez que se obligó a la población indígena a trasladarse al espacio denominado por los españoles «barrios»o parcialidades de indios". Ver Sánchez, 2004, p. 65.

26. Cfr. Gutiérrez, 1999, pp. 271-274.

27. Gutiérrez, 1999, pp. 261-263.

28. Gutiérrez, 1999, pp. 269-271.

29. Gutiérrez, 1999, p. 269. Cfr. también Chávez, 2010, pp. 75-76. 
30. De hecho, San Diego es descrito como "a extramuros de la villa"; ver Ochoa, 1953, p. 14.

31. Cfr. Gutiérrez, 1999, pp. 263-269.

32. Gutiérrez, 1999, pp. 261-271.

33. Gutiérrez, 1999, pp. 271-274.

34. Gutiérrez, 1999, pp. 274-281.

35. Cfr. Wright, 1989, pp. 13-44 (1994 y 2006 en versión electrónica), en: «http:// www.paginasprodigy.com/dcwright/vida.htm, consultado el 10 de abril de 2013».

36. Según el Padrón de 1648, conteo que incluía en pueblo de San Marcos; ver Gutiérrez, 2003, p. 354.

37. López, 2001, p. 51.

38. Diversas cédulas reales corrieron desde el siglo XVI buscando eliminar la práctica de facto de la adquisición de bienes por parte del clero, tanto regular como diocesano, que pueden consultarse en: “500 años de México en documentos”, «http://www.biblioteca.tv/artman2/ publish/index.shtml».

39. Urroz, 2009, p. 132.

40. Russo, 2007, p. 4, en: «http://terrabrasilis.revues.org/388», consultado el 29 de abril de 2013. Ver también Russo, 2005.

41. Russo, 2007, p. 9.

42. Fernández, citada en Gonzalbo, 2009, p. 49.

43. Fernández, citada en Gonzalbo, 2009, p. 49.

44. Russo, 2007, p. 13.

45. Russo, 2007, p. 13.

46. Russo, 2007, p. 14.

47. A. Russo, 2007, p. 6 .

\section{RESÚMENES}

El presente artículo expone los resultados preliminares de un análisis de imagen que pretende contribuir a despejar algunas incógnitas persistentes sobre la villa de las Aguas Calientes (Nueva España), haciendo uso de fuentes primarias escritas y gráficas, especialmente una cartografía pictórica de 1730. Los resultados muestran una imagen idealizada que confirma la idea de la invención del territorio como estrategia subjetiva.

Este artigo apresenta os resultados preliminares da análise de imagem, que visa ajudar a dissipar algumas incertezas persistentes sobre a cidade de Aguas Calientes (Nova Espanha), utilizando fontes primárias pictórica e por escrito, especialmente no mapeamento pictórico da 1730 . Os resultados mostram uma imagem idealizada que confirma a ideia da invenção do território como uma estratégia subjetiva.

This paper presents the preliminary results of image analysis that aims to help clarify certain questions lingering on historiography of Villa of Aguas Calientes (New Spain), using primary written and graphic sources, especially a 1730 pictorial mapping. The text confirms the idea that the process of drawing territory, invents it as subjective strategy. 
ÍNDICE

Keywords: invention of territory, parish structure of urban space, circular realism Índice geográfico: Aguascalientes, México

Índice cronológico: 1730

Palabras claves: invención del territorio, estructura parroquial del espacio urbano, realismo circular

Palavras-chave: invenção do território, a estrutura paroquial de espaço urbano, realismo circular

\section{AUTORES}

MARCO ALEJANDRO SIFUENTES SOLÍS

Doctor en Arquitectura - Universidad Autónoma de Aguascalientes

JORGE CARLOS PARGA RAMÍREZ

Doctor en Arquitectura - Universidad Autónoma de Aguascalientes 